\title{
Fetal Chimerism and Fetal Thymic Transplantation
}

\section{Bhattacharya $\mathbf{N}^{\star}$ and Sengupta $\mathbf{P}$}

Department of Regenerative Medicine and Translational Science, Calcutta School of Tropical Medicine, Kolkata, India

${ }^{*}$ Corresponding author: Prof. Dr. Niranjan Bhattacharya, Department of Regenerative Medicine and Translational Science, Calcutta School of Tropical Medicine, Kolkata, India, Tel: 00919830038158; E-mail: sanjuktaniranjan@gmail.com

Rec date: February 28, 2018; Acc date: March 13, 2018; Pub date: March 16, 2018

Copyright: (c) 2018 Bhattacharya N, et al. This is an open-access article distributed under the terms of the creative commons attribution license, which permits unrestricted use, distribution, and reproduction in any medium, provided the original author and source are credited.

\begin{abstract}
Fetal tissue transplantation is an attractive field of modern medicine that can have immense application in treating several refractile conditions. Fetal tissue transplantation is an allogeneic transplantation procedure and like any allogeneic transplantation they contribute towards the formation of a chimera at the cellular and tissue level grossly and can be classified as a macro chimerism. The fetus during the time of pregnancy also takes part in microchimerism through fetomaternal cell trafficking where there is an exchange of the maternal and the fetal cells through the blood-placental barrier. Apart from the creation of a stable chimerism, fetal tissues also play a role in healing. Fetal thymic transplantation is one of the most exciting applications of regenerative medicine which has also been discussed briefly with some case studies.
\end{abstract}

Keywords:

Fetal tissue; Blood-placental barrier; Di George's syndrome

\section{Introduction}

On November 10, 1988, Dr. Curt Feed and his colleagues did a fetal brain tissue transplantation in a 52 -year-old patient suffering from Parkinson's disease. Since then fetal tissue transplantation has come a long way [1]. According to the Guttmacher institution between 2010-2014, approximately 56 million abortions occur globally [2]. Most of these fetuses are thrown away in the hospital pits and incinerators as a biological trash material without realizing its true potentialities. Since 1999, Bhattacharya et al. has been practicing the application of fetal tissue transplantation freshly collected and fully screened from consenting mothers in a variety of refractory illnesses including fetal thymus [3]. Fetal thymic transplantation deserves special mention as it has been successfully used to rectify patients suffering from Di George's Syndrome, Hodgkin's and Non-Hodgkin's Lymphoma. These applications of allogeneic fetal thymus transplantation led to the formation of a stable chimeric model without its rejection.

\section{Chimerism and Fetal Tissue}

The fetal chimerism can be of two types the micro and macro chimera. During pregnancy, fetomaternal chimerism is a welldocumented phenomenon where there is believed to be some exchange of cells between the mother and the fetus through the blood-placental barrier. Herzenberg et al. showed the presence of fetal genetic material in the peripheral circulation of the mother [4]. These fetal cells in the maternal system can reside for a long time and its earliest detection can be reported at 4-5 weeks of postpartum with a further decline in the maternal blood post 6 months [5,6]. Pertaining to the previous point, some believe, there can be a $100 \%$ clearance of chimerism at the post-partum stage [7]. Others believe that this chimerism can persist in the maternal system for long even after post-partum [8]. Other examples of fetal micro-chimerism have shown to exist in the maternal bone marrow system also $[9,10]$.

Macro-chimerism is a phenomenon that is expressed or observed at the cell tissue level. Fetal tissue transplantation below 15 weeks or so in the pre-HLA development phase has shown to survive without any graft versus host rejection for longer periods $[11,12]$. Tolerance and accommodation can be probably two important biological phenomena contributing towards the successful survivability of the macrochimerism. Further, it was observed that the fetal tissue can develop its own microenvironment by downgrading the molecular antennas responsible for recognition and rejection by the host's T-cells [13].

Accommodation normally up-regulates the complement system thereby developing a resistance to cytotoxic activities of the host's immune system [14,15]. PI3K and heme oxygenase pathways are responsible for the process of accommodation and successful fetal survival during the time of pregnancy which can be correlated with the survival of the fetus without rejection post-transplantation in the patient's body. The concept of whole embryo transplantation is also very interesting as the trophoblastic layer of the embryo can act as a barrier against the T-cell activities.

\section{Advantages of Fetal Tissue Transplantation}

The fetus including the fetal tissues is rich in stem cells, progenitor or fetal cells. They express low mRNA transcripts of HLA-G and the mesenchymal stem cell content of the fetus can have an antiinflammatory effect as observed under in vitro conditions $[16,17]$. Fetal tissues can even heal injuries efficiently and rapidly without the formation of scar tissues or fibrosis. These cells or tissues, when transplanted in vivo, has shown to develop their own microenvironment without getting rejected. This is due to the fact that most of the fetal tissues are collected before 15 weeks of gestation and 
as they remain in a pre-immune phase or a pre-HLA stage it remains untargeted by the host's immune system [18].

Application of fetal tissue in medicine and surgery can be also an alternative to organ transplantation. Currently, organ transplantation can be allogeneic or xenogeneic transplantation. Currently, the waiting period and the cost of treatment for receiving an organ transplant globally is a major limiting factor often leading to high mortality rates. Another major problem in organ transplantation is graft versus host rejection. Organ transplantation requires HLA matching and more the match, more is the less use of immunosuppressant and antiinflammatory drugs and vice versa. Long-term use of such drugs can often lead to side effects like host immunosuppression [3]. Also, the correct age match of the organ donor and recipient is an important parameter while performing organ transplantation. Zoogenesis or transmission of animal infection to humans can be a cause of concern in xeno-transplantation.

Keeping in mind the above limitations of organ transplantation the clinical applications of fetal tissues and whole fetal organs can be a very effective therapeutic approach due to three main reasons 1 . Pre-HLA nature of the fetus 2. A potent hub for potent progenitor and stem cells 3. Collection is easy if proper ethics is maintained.

\section{Case Studies of Fetal Thymus Transplantation}

In 1974, a 12-week fetal thymus tissue was collected and transplanted in small sections at the abdominal muscles of an infant patient suffering from Di George's Syndrome, follow up studies after 2 weeks showed remission of the respiratory infection with no evidence of Graft versus Host Diseases (GvHD). Within a month's time, the lymphocytes reached a normal level in the blood circulation [19-22].

Similar studies were conducted in additional patients where 5 years follow up studies of the patients reported normal T-cell count except in few cases where the T-cell count decreased post-transplantation. Longterm follow-up studies further revealed that 5 of the subjects had a long-lasting beneficial effect with the restoration of normalcy even after 20 years. One of the patients however expired because of cardiomyopathy [23-26].

Syngeneic fetal thymic cells have been successfully transplanted in case of a child suffering from severe combined immunodeficiency (SCID) due to the unavailability of an HLA matched identical donor for bone marrow transplantation. The patient is now leading a healthy and normal life without the need of any further treatment [27-29].

Between 1999 and 2006, Bhattacharya et al., transplanted fetal thymus (age between 12 to 16 weeks) in the axilla of 7 patients (age between 13 and 64 years, 2 females and 5 males) who were suffering from both Hodgkin's and Non-Hodgkin's Lymphoma after patient informed consent and ethical clearance was provided. These fetal thymuses were all freshly collected and screened for HIV-I, II, Hepatitis, Malaria, CMV, Syphilis in 7 patients. Paracetamol was given to all the patients post-transplantation. One month follow up studies revealed the WBC count to be between 24,000 to $42,000 / \mathrm{mm}^{3}$ without any prevalence or observation of graft versus host disease. Histology studies further revealed the development, growth, and differentiation of the fetal thymus in vivo. In one of the Non-Hodgkin's lymphoma case, the 16-week old fetal tissue was removed due to a massive rise in the $\mathrm{WBC}$ and was thought to be of oncogenic in nature. Post removal there was a decrease in the abnormal WBC level and restoration of a normal count [30].

\section{Fetal Thymus Transplantation and Chimerism}

As already mentioned before, like other fetal tissues, none of the fetal thymic transplants exhibited any host versus graft disease along with mono-nuclear invasion or endarteritis. This led to the successful creation of a thymic fetal and host macro-chimerism. Alleviation of symptoms in almost all the cases was observed probably due to the homing of the fetal thymic progenitor cells or its cytokine-based support system. The fetal thymic tissue like other fetal tissues is also resistant to stress and hypoxic conditions [31]. The less vascularity of the fetal tissue can also avoid the T-cell surveillance and other immune complexes. The extracellular matrix (ECM) plays a major part in healing and likewise, the fetal tissue ECM also provides support for cytokines and a unique matrix consisting of integrin and non-integrin receptors for cell adhesion, mobilization, and migration [31,32]. These are expected to be some of the major factors that may play in the creation of a successful fetal chimeric model with immense potential in clinical medicine although it is still in its infancy stage.

Applications of embryonic stem cells and induced pluripotent stem cells to rectify thymic disorders

Human embryonic and induced pluripotent stem cells are another attractive field of stem cell therapy to rectify many disorders of the immune system including the thymus. Both being pluripotent in nature have the ability to differentiate into the entire three germ layers the endoderm, ectoderm and the mesoderm and can therefore be used to differentiate into thymic cells for treating thymic disorders.

In one such study by Inami et al. in 2011, mouse induced pluripotent stem cells (miPSC) were able to create thymic epithelial progenitor cells (TEPCs) and were further differentiated into medullary TECs (mTECs) in the presence of fibroblast growth factors, bone morphogenetic protein, receptor activated nuclear factor B ligand and $\mathrm{LiCl}$. Gene expression studies further analyzed the presence of Hoxa3, Pax1, Pax 9 along with cell surface markers like EpCAM, MTS24 on the 14th day of the iPSC differentiation [33].

Normally the thymus is the main organ for developing the immune tolerance by eliminating the auto reactive $\mathrm{T}$ cells. The thymic epithelial cells or TECs are the major cells of the thymic microenvironment responsible for the functional development of the T cells [34]. Thymic epithelial cells (TECs) obtained from iPSCs could also be used to develop tolerance against iPSC derived graft through the process of cotransplantation. This process can help in the production of $\mathrm{T}$ cells that are resistant to stem cell auto-antigens and neo-antigens thereby potentially preventing the transplantation rejection. Further, it can have a positive impact on cell-based regenerative medicine therapies [35].

Like iPSCs, human Embryonic Stem Cells (hESCs) are attractive sources for the production of thymus epithelium in vitro. Xiaoning et al. reported the production of thymic epithelium progenitor-like cells (TEPLCs) in the presence of Activin, Retinoic Acid, and BMP. Gene expression studies revealed the presence of thymic specific genes like FOXN1 and even functional thymic markers such as MHC II, AIRE post-transplantation. The group also noted that these TEPLCs derived thymic epithelium could further aide mouse thymopoiesis in T-cell deficient mice and also generate human $\mathrm{T}$ cell in NOD/SCID mice when transplanted with human hematopoietic stem cells [36]. Similar works pertaining to generation of thymic epithelial progenitors (TEPCs) are also reported by Parent et al., The generated TEPCs further went on to form matured and functional thymus epithelial cells (TECs) which supported the $\mathrm{T}$ cell development in thymus deficient 
mice. These $\mathrm{T}$ cells were functional in vivo and showed the ability to proliferate under in vitro conditions also [37]. According to Min Su et al., the efficiency of differentiating human embryonic stem cells (hESCs) into functional thymic epithelial progenitor's cells (TEPCs) and functional thymic epithelial cells (TECs) is low. Also, in vivo co transplantation studies with human hematopoietic precursors have reported very low human $T$ cell generation [34]. They further developed a process where TEPCs from hESCs can be differentiated into matured TECs and form the thymic architecture including longterm development of functional mouse $\mathrm{T}$ cells or high level of human $\mathrm{T}$ cells after co-transplantation with human hematopoietic precursors [34].

Thymus transplantation still remains the best method to treat thymic defect. However, acute shortage of thymus transplant donors including the need for HLA, ABO matching is a major hurdle in thymus transplantation [38,39]. Newer treatment concepts like regenerative medicine have ushered a new era in clinical science. In cell therapy, human embryonic stem cells and induced pluripotent stem cells have shown potentialities to produce thymic epithelial progenitor cells TEPCs and functional thymic epithelial cells TECs. However, most of them are limited to in vitro and in vivo animal studies as the scope of translating these studies into clinical trials is yet not feasible. It still remains unclear to what extent these hESCs, iPSCs can differentiate into functional TECs from TEPs and support thymopoiesis in vivo $[40,41]$. Considering the limitations of iPSC, hESC, fetal thymus transplantation can be an extremely attractive option. The process of fetal thymus transplantation and its collection is simple and can be easily done by a trained physician in a surgical OT with minimal infrastructure.

\section{Discussion}

\section{Ethics of fetal tissue, hESC and iPSC application}

Induced pluripotent stem cell, human embryonic stem cell research, and fetal tissue transplantation are currently under ethical scrutiny by different religious, political and scientific groups. Fetal thymus in all the above case studies was collected from volunteers or mothers who gave their consent to donate their aborted fetuses for the betterment and advancement of medical science and research. Just like mothers have the right to decide to terminate or continue with their pregnancy similarly medical researchers and clinicians should also have the liberty to decide whether to utilize a discarded healthy fetus for a better clinical outcome in many end stage diseases when all current standard mode of treatment has been exhausted and failed [3]. Said that there are many instances where moral ethical values are not always practiced especially in developing countries where human exploitation is recorded the highest. In poor and developing nations, many pregnant mothers can be forced to undergo abortion in exchange for monetary gains resulting into massive unethical malpractices and exploitations. Such challenges can be countered only through strict vigilance and formulating stringent guidelines and laws condemning such malpractices and exploitations through creations of severe punishment if found guilty.

The second moral and ethical question that arises in fetal tissue transplantation is when should be a fetus considered to be an individual with life and whether it is justified to destroy a life for medical gains? Normally most of the fetal tissues are collected from the first trimester upto the early second trimester. Ethical dilemmas and issues come into play when mid second trimester fetuses are collected as it is believed that during this period a fetus starts to attain personhood and become live. However, fetal tissues collected from early second trimester abortions should be immediately used for fetal tissue transplantations after the woman has given her consent [42]. Nonetheless, the above topic is still highly debatable and requires a thorough validation before coming to a particular view.

Embryonic stem cell research from the beginning itself has been associated with ethical issues pertaining to the destruction of an embryo. Formation of teratomas as reported in some cases has further increased the doubt about the potentialities of hESCs as a source for clinical stem cell therapy $[43,44]$. Similar, ethical dilemmas are also associated with induced pluripotent stem cells and its clinical applications like the use of proto-oncogene transcription factors klf-4, c-myc, use of viral vectors. One study stated that human iPSCs develop teratomas more efficiently and faster than hESCs irrespective of their site of injection [45-48]. Compared to this, fetal tissue, which is also a source of pluripotent, multipotent stem and progenitor cells can be a better alternative to regenerative medicine.

\section{Conclusion}

Successful fetal tissue transplantation be it thymic or any other tissue is a unique example of a stable chimera model where two different genetic constitutes stay together in vivo without the incidence of rejection. However, there are still many unanswered questions. The mechanism by which a stable chimerism is maintained by the fetus and the fetal tissue vivo is still under intense speculation and further molecular investigations are required. To what degree or extend the rejection does not occur is also another interesting area of molecular immunology. The fate of the fetus post-transplantation in vivo is another important phenomenon. Whether the fetus gets dissolved or remains intact or grows is an important scientific quest. In the above study the fetal thymus tissue was shown to develop over time and in another study by the same group, Bhattacharya et al., has shown that a fetal tissue removed after 12 years since its transplantation in a patient cured from the disease has shown to be intact in nature without any signs of rejection [13].

\section{References}

1. Panikkar B, Smith N, Brown P (2012) Reflexive research ethics in fetal tissue xenotransplantation research. Account Res 19: 344-369.

2. http://www.who.int/reproductivehealth/news/abortion-rates/en/

3. Bhattacharya N, Stubblefield P (2013) Human fetal tissue transplantation, (1st edn), Springer Verlag, London, United Kingdom.

4. Herzenberg LA, Bianchi DW, Schroder J, Cann HM, Iverson GM (1979) Fetal cells in the blood of pregnant women: Detection and enrichment by fluorescence-activated cell sorting. Proc Natl Acad Sci USA 76: 1453-1455.

5. Thomas MR, Williamson R, Craft I, Yazdani N, Rodeck CH (1994) Y chromosome sequence DNA amplified from peripheral blood of women in early pregnancy. Lancet 343: 413-414.

6. Ariga H, Ohto H, Busch MP, Imamura S, Watson R, et al. (2001) Kinetics of fetal cellular and cell-free DNA in the maternal circulation during and after pregnancy: Implications for noninvasive prenatal diagnosis. Transfusion 41:1524-1530.

7. Lo YMD, Zhang J, Leung TN, Lau TK, Chang AMZ, et al. (1999) Rapid clearance of fetal DNA from maternal plasma. Am J Hum Genet 64: 218-224.

8. Invernizzi P, Biondi M, Battezzati P, Perego F, Selmi C, et al. (2002) Presence of fetal DNA in maternal plasma decades after pregnancy. Hum Genet 110: 587- 591 . 
9. Adams KM, Lambert NC, Heimfeld S, Tylee TS, Pang JM, et al. (2003) Male DNA in female donor hapheresis and CD34-enriched products. Blood 102: 3845-3857.

10. Donoghue K, Chan J, de la Fuente J, Kennea N, Sandison A, et al. (2004) Microchimerism in female bone marrow and bone decades after fetal mesenchymal stem cell trafficking in pregnancy. Lancet 364: 179-182.

11. Fan X, Ang A, Pollock Bar Ziv SM, Dipchand AI, Ruiz P, et al. (2004) Donorspecific B-cell tolerance after ABO-incompatible infant heart transplantation. Nat Med 10: 1227-1233.

12. Nagata H, Ito M, Cai J, Edge A, Platt JL, et al. (2003) Treatment of cirrhosis and liver failure in rats by hepatocyte xenotransplantation. Gastroenterology 124: 422-431.

13. Bhattacharya N, Stubblefield P (2013) Fetomaternal cell trafficking: A window into the long-term Health effects of treating Disease with Fetal Cell/Tissue Transplants? 1st (edn), Human Fetal Tissue Transplantation, Springer-Verlag, London, United Kingdom.

14. Koch CA, Khalpey ZI, Platt JL (2004) Accommodation: Preventing injury in transplantation and disease. J Immunol 172: 5143-5148.

15. Lynch RJ, Platt JL (2008) Accommodation in organ transplantation. Curr Opin Organ Transplant 13: 165-170.

16. Weiss ML, Anderson C, Medicetty S, Seshareddy KB, Weiss RJ, et al. (2008) Immune properties of human umbilical cord Wharton's jellyderived cells. Stem Cells 26: 2865- 2874.

17. Roelen DL, van der Mast BJ, Anker PS, Kleijburg C, Eikmans M, et al. (2009) Differential immunomodulatory effects of fetal versus maternal multipotent stromal cells. Hum Immunol 70: 16-23.

18. Bhattacharya N, Stubblefield P (2013) Treatment by human fetal neuronal tissue transplant at a heterotopic site in the axilla in case of motor neuron disease: A report of two cases. (1st edn), Human Fetal Tissue Transplantation, Springer Verlag, London, United Kingdom.

19. Hong R, Touraine JL (1976) Transplantation and clinical immunology. Villeurbanne 1: 215-221.

20. Bhattacharya N, Stubblefield P (2013) Fetal Thymus Transplantation in Di George Syndrome. (1st edn), Human Fetal Tissue Transplantation, Springer Verlag, London, United Kingdom.

21. Touraine JL (2000) Perinatal fetal-cell and gene therapy. Int J Immunopharmacol 22: 1033-1040.

22. Cleveland WW, Fogel BS, Brown WT, Kay H (1968) Foetal thymus transplant in a case of DiGeorge syndrome. Lancet 2: 1211-1214.

23. August CS, Rosen FS, Miller RM (1970) Implantation of a fetal thymus, restoring immunological competence in a patient with thymus aplasia. Lancet 2: 1210-1212.

24. Gatti RA, Gershanik JJ, Levkoff AH (1972) DiGeorge syndrome associated with combined immunodeficiency. J Pediatr 81: 920-926.

25. Biggar WD, Park BY, Stutman O, Gajl-Peczalska K, Good RA (1975) Fetal thymus transplantation: Experimental and clinical observations. Birth Defects Orig Artic Ser 11: 361-366.

26. Jose DG, Barnes EJR, Rossiter EJR, Myers NA, Fitzgeraldtt MG (1974) Reconstitution of cellular immune function in a child with thymic aplasia by fetal thymus grafting. Aust N Z J Med 4: 267-273.

27. Touraine JL (1983) Bone marrow and fetal liver transplantation in immuno-deficiencies and inborn errors of metabolism: Lack of significant restriction of T-cell function in long-term chimeras despite HLA mismatch. Immunol Rev 1: 103-121.
28. Reilly RJ, Kapoor N, Kirkpatrick D (1983) Transplantation of hematopoietic cells for lethal congenital immunodeficiencies. Birth Defects Orig Artic Ser 19: 129-137.

29. Touraine JL (1997) Stem cell transplantation. Fetal therapy, Cambridge University Press, Cambridge, United Kingdom.

30. Bhattacharya N, Mukherjee KL, Chettri MK, Banerjee T, Bhattacharya S, et al. (2001) A unique experience with human pre-immune (12 weeks) and hypo-immune (16 weeks) fetal thymus transplant in a vascular subcutaneous axillary fold in patients with advanced cancer: a report of two cases. Eur J Gynaecol Oncol 22: 273-277.

31. Bhattacharya N (2004) Fetal cell/tissue therapy in adult disease: A new horizon in regenerative medicine. Clin Exp Obstet Gynecol 31: 167-173.

32. Yrjö TK, Emilia K, Vasily S, Wagner HD, Jaakko L, et al. (2011) Extracellular matrix and tissue regeneration. In: Regenerative medicine. Dordrecht, Springer, London, United Kingdom.

33. Inami $\mathrm{Y}$, Yoshikai T, Ito $S$, Nishio $\mathrm{N}$, Suzuki $\mathrm{H}$, et al. (2011) Differentiation of induced pluripotent stem cells to thymic epithelial cells by phenotype. Immunol Cell Biol 89: $314-321$.

34. Su M, Hu R, lin , Yan Y, Song Y, et al. (2015) Efficient in vitro generation of functional thymic epithelial progenitors from human embryonic stem cells. Nature Scient Rep 5: 9882 .

35. Scheiner ZS, Talib S, Feigal EG (2014) The potential for immunogenicity of autologous induced pluripotent stem cell-derived therapies.J Biol Chem 289: 4571-4577.

36. Sun $\mathrm{X}, \mathrm{Xu}$ J, Lu H, Liu W, Miao Z, et al. (2013) Directed differentiation of human embryonic stem cells into thymic epithelial progenitor-like cells reconstitutes the thymic microenvironment in vivo. Cell Stem Cell 13: 230-236.

37. Parent AV, Russ HA, Khan IS, LaFlam TN, Metzger TC, et al. (2013) Generation of functional thymic epithelium from human embryonic stem cells that supports host T cell development. Cell Stem Cell 13:1-2.

38. Markert ML, Devlin BH, Chinn IK, McCarthy EA, Li YJ (2008) Factors affecting success of thymus transplantation for complete DiGeorge anomaly. Am J Transplant 8: 1729-1736.

39. Green MD, Snoeck HW (2011) Novel approaches for immune reconstitution and adaptive immune modeling with human pluripotent stem cells. BMC Med 9: 51

40. Bennett AR, Farley A, Blair NF, Gordon J, Sharp L, et al. (2002) Identification and characterization of thymic epithelial progenitor cells. Immunity 16: 803-814.

41. Rossi SW, Jenkinson WE, Anderson G, Jenkinson EJ (2006) Clonal analysis reveals a common progenitor for thymic cortical and medullary epithelium. Nature 441: 988-991.

42. Sanders LM, Giudice L, Raffin TA (1993) Ethics of fetal tissue transplantation in fetal medicine. West Med 159: 400-407.

43. Baker M (2009) Why hES cells make teratomas. Nature Rep Stem Cells 36: 1-2.

44. Blum B, Benvenisty N (2008) The tumorigenicity of human embryonic stem cells. Adv Cancer Res 1: 133-158.

45. Aranda GI, Mejia RV, Bueno C (2010) Human induced pluripotent stem cells develop teratoma more efficiently and faster than human embryonic stem cells regardless the site of injection. Stem Cells 28: 1568-1570.

46. Mukherjee S, Thrashe AJ (2011) Molecular Therapy. Am Soc Gene Cell Ther 19: 1188-1190.

47. Nakagawa M, Takizawa N, Narita M, Ichisaka T, Yamanaka S (2010) Promotion of direct reprogramming by transformation-deficient Myc. Proc Natl Acad Sci USA 107: 14152-14157.

48. Mari O, Takahashi K (2015) Present and future challenges of induced pluripotent stem cells. Philos Transact Royal Soc B 370: 20140367. 